\title{
In situ testing and nonlinear modelling for a cable-stayed timber footbridge
}

\author{
Daniele Bortoluzzi ${ }^{1}$, Fabio Casciati ${ }^{1}$, Sara Casciati $^{2}$ and Lucia Faravelli ${ }^{1}$ \\ ${ }^{1}$ DICAR, University of Pavia, 27100 Pavia, Italy \\ ${ }^{2}$ DICA, University of Catania, 96100 Siracusa, Italy
}

\begin{abstract}
The authors had the chance to collect structural response measurements of a cable-stayed gluedlaminated-timber (GLT) footbridge located in Farra d'Alpago (not far from the town of Belluno, in NorthEastern Italy). A consistent geometrically nonlinear finite element model was generated and its parameters were calibrated on the experimental data. Finally, a model validation was carried out.
\end{abstract}

\section{Introduction}

The design of pedestrian timber bridges is becoming popular in those areas where the structural system has to fit well with the surrounding landscape, as it occurs in mountain villages. The use of timber, and/or timber coupled with steel elements, is appreciated, from both the designer and the costumer, due to several aspects spanning from the economy to the environment, from the architecture to the management. The glued laminated timber (GLT) technology, in particular, allows the designer to cover footbridge spans longer than $100 \mathrm{~m}$. As a consequence of the resulting slenderness and the material coupling, the problems of foreseeing and mitigating the vibrations, induced by human loading (walking and running), wind action and so on, is not straightforward and in situ tests are often a must.

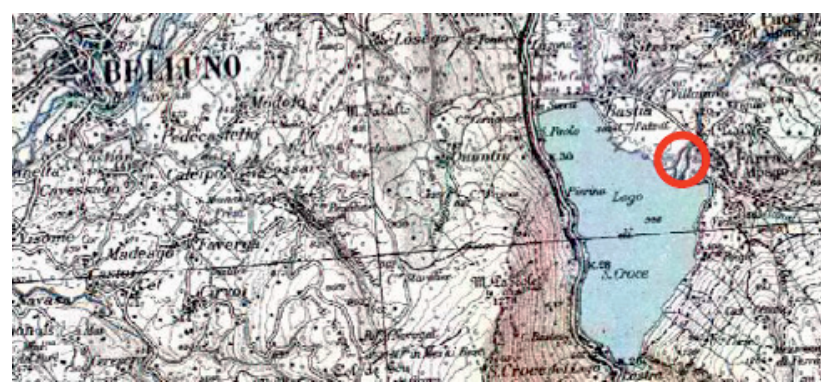

Figure 1. Location of the footbridge under study (red circle).

The authors had the chance to acquire measurements of the structural response of the GLT cable-stayed footbridge located in Farra d'Alpago (not far from the town of Belluno), which connects the two side of the channel outlet of the Lake "Santa Croce" (Figure 1). In this paper the records from a first experimental campaign carried out on November 7, 2013 are presented, analyzed and discussed in view of the generation of a sophisticated, geometrically nonlinear numerical model.

\section{The case study}

To harmonize the crossing with the naturalistic area surrounding the structure, only timber (or better Glued Laminated Timber GLT beams of high strength BS14 and BS16 according to the DIN1052 document) and steel (of high strength S355J0 according to the UNI EN10025 code) were used as structural material, limiting the use of concrete to the foundation.

\subsection{The structural scheme}

The static scheme is the standard cable-stayed scheme (Figure 2). The span is about $110 \mathrm{~m}$ subdivided into three segments: the length of the central segment is $65 \mathrm{~m}$, while the two external segments show a length of $22.5 \mathrm{~m}$. The free crossing width of the deck is $3.2 \mathrm{~m}$. The two antennas show a height of $16 \mathrm{~m}$. The deck is realized linking two main GLT beams with transversal U-shape steel tubular elements, as shown in Figure 3.

\subsection{A consistent FE model}

Following the technical documentation provided by the designers, Eng. Stefano Boranga and Arch. Lio 
Parcianello, and the timber elements producer Rubner Holzbau S.p.A. of Bolzano, a sophisticated numerical (finite element, FE) model was generated using the Marc MENTAT2010 software. The model had the preliminary use of facilitating the sensor placement. When the results from the first experimental campaign code had become available, the finite element model was then calibrated and validated.
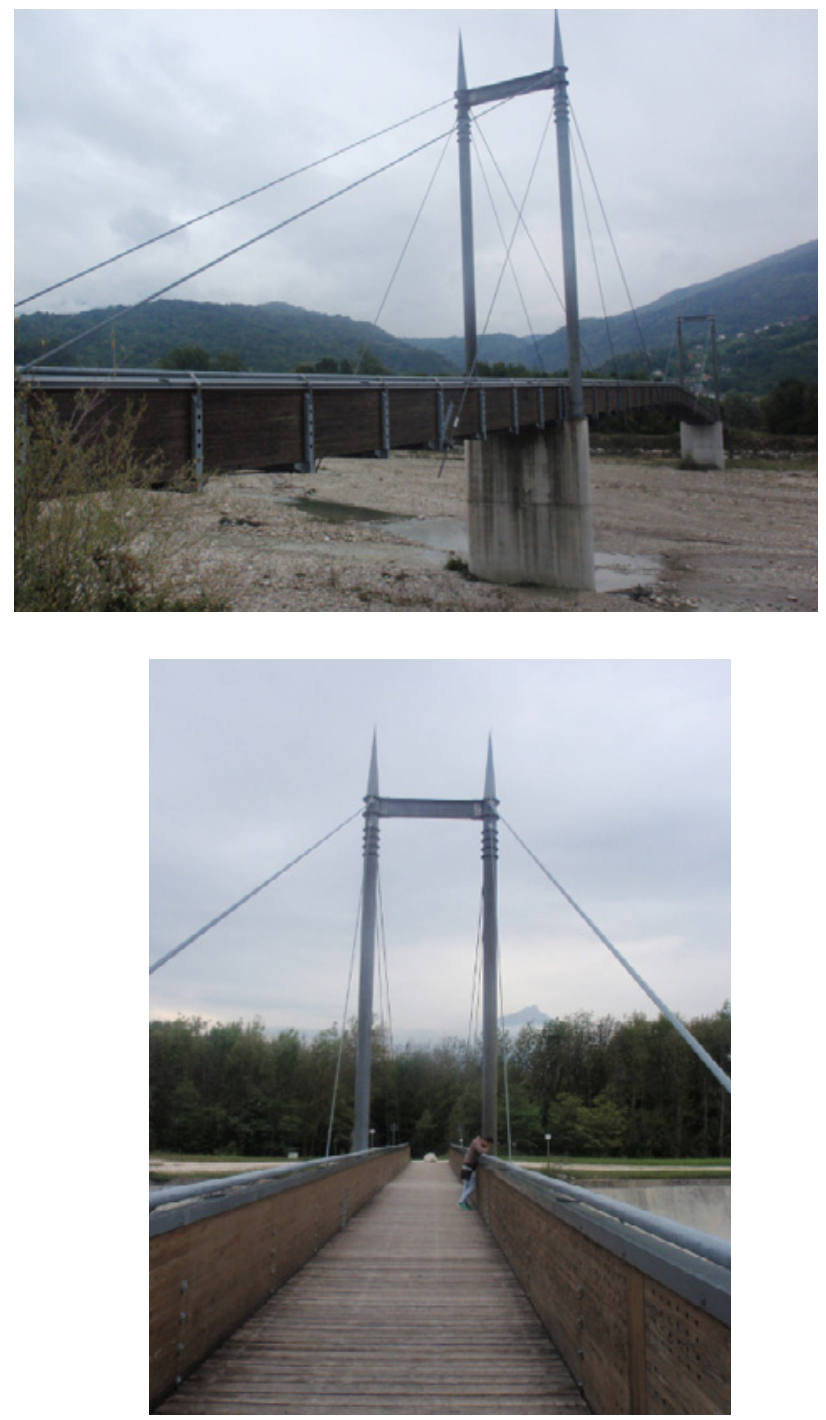

Figure 2. Lateral view of the pedestrian bridge under study (left), and view of the deck (right) from above.

\subsection{A first experimental campaign}

The experimental campaigns, carried out in situ on November 7, 2013, resulted in collecting records of acceleration at several relevant points along the deck of the bridge, using tri- and mono-axial accelerometers, under different external excitations (wind load, pedestrian's walking and running across the bridge Figure 4). A wireless technology developed by some of the authors [1] was adopted to collect and transmit the data.
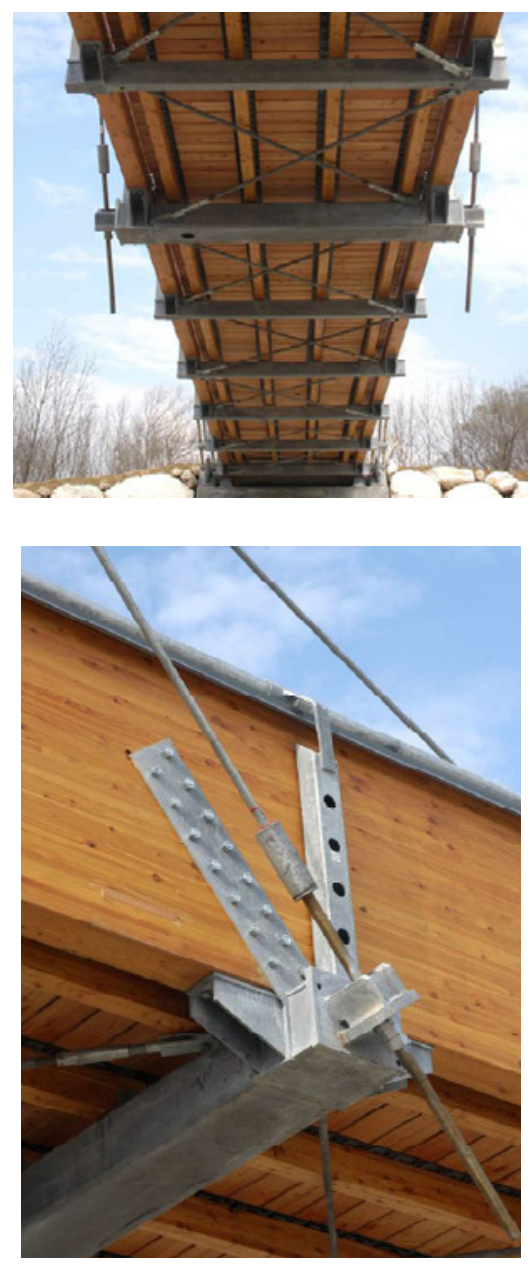

Figure 3. Deck details. View from the bottom (left) and connection cable-deck (right).

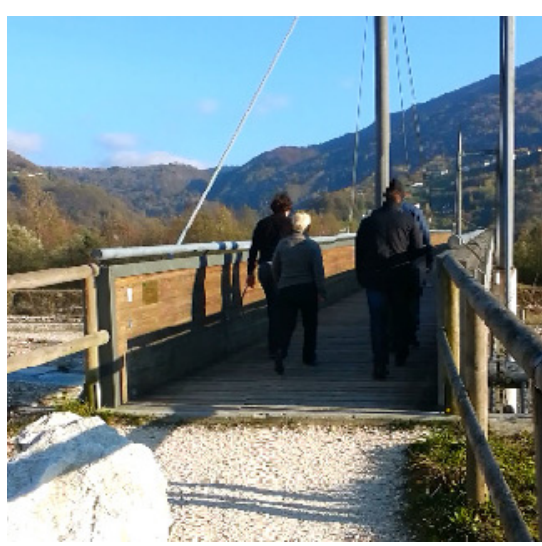

Figure 4. Photo during the human-induced-vibration during a particular test (walking).

\section{References}

1. Z. Chen and F. Casciati, A low-noise, real-time, wireless data acquisition system for structural monitoring applications, Structural Control and Health Monitoring, Article first published online: 17 DEC 2013 | DOI: 10.1002/stc. 1636 